\title{
S-allylmercaptocysteine reduces carbon tetrachloride-induced hepatic oxidative stress and necroinflammation via nuclear factor kappa B-dependent pathways in mice
}

\author{
Jia Xiao $\cdot$ Emily C. Liong $\cdot$ Ming-Tat Ling $\cdot$ \\ Yick-Pang Ching $\cdot$ Man-Lung Fung • \\ George L. Tipoe
}

Received: 26 February 2011/Accepted: 1 June 2011/Published online: 18 June 2011

(c) The Author(s) 2011. This article is published with open access at Springerlink.com

\begin{abstract}
Purpose To study the protective effects and underlying molecular mechanisms of SAMC on carbon tetrachloride $\left(\mathrm{CCl}_{4}\right)$-induced acute hepatotoxicity in the mouse model.

Methods Mice were intraperitoneally injected with $\mathrm{CCl}_{4}$ (50 $\mu \mathrm{l} / \mathrm{kg}$; single dose) to induce acute hepatotoxicity with or without a 2-h pre-treatment of SAMC intraperitoneal injection $(200 \mathrm{mg} / \mathrm{kg}$; single dose). After $8 \mathrm{~h}$, the blood serum and liver samples of mice were collected and subjected to measurements of histological and molecular parameters of hepatotoxicity.

Results SAMC reduced $\mathrm{CCl}_{4}$-triggered cellular necrosis and inflammation in the liver under histological analysis. Since co-treatment of SAMC and $\mathrm{CCl}_{4}$ enhanced the expressions of antioxidant enzymes, reduced the nitric oxide (NO)-dependent oxidative stress, and inhibited lipid peroxidation induced by $\mathrm{CCl}_{4}$. SAMC played an essential antioxidative role during $\mathrm{CCl}_{4}$-induced hepatotoxicity. Administration of SAMC also ameliorated hepatic inflammation induced by $\mathrm{CCl}_{4}$ via inhibiting the activity of
\end{abstract}

J. Xiao, E. C. Liong, G. L. Tipoe contributed equally to this work.

J. Xiao · E. C. Liong · Y.-P. Ching · G. L. Tipoe $(\bowtie)$

Department of Anatomy, Li Ka Shing Faculty of Medicine,

The University of Hong Kong, L1-41, Laboratory Block,

21 Sassoon Road, Pokfulam, Hong Kong SAR, China

e-mail: tgeorge@hkucc.hku.hk

M.-L. Fung

Department of Physiology, Li Ka Shing Faculty of Medicine,

The University of Hong Kong, Hong Kong SAR, China

\section{M.-T. Ling}

Australian Prostate Cancer Research Centre-Queensland and Institute of Health and Biomedical Innovation,

Queensland University of Technology, Brisbane, QLD, Australia
$\mathrm{NF}-\kappa \mathrm{B}$ subunits $\mathrm{p} 50$ and $\mathrm{p} 65$, thus reducing the expressions of pro-inflammatory cytokines, mediators, and chemokines, as well as promoting pro-regenerative factors at both transcriptional and translational levels.

Conclusions Our results indicate that SAMC mitigates cellular damage, oxidative stress, and inflammation in $\mathrm{CCl}_{4}$-induced acute hepatotoxicity mouse model through regulation of NF- $\kappa \mathrm{B}$. Garlic or garlic derivatives may therefore be a potential food supplement in the prevention of liver damage.

Keywords Liver injury - S-allylmercaptocysteine · Carbon tetrachloride - Oxidative stress . Necroinflammation $\cdot$ Nuclear factor $\kappa \mathrm{B}$

\section{Introduction}

As a potent hepatotoxin, carbon tetrachloride $\left(\mathrm{CCl}_{4}\right)$ continues to serve as an important substance in medicinal research, particularly in the investigation of hepatotoxininduced liver diseases [1]. $\mathrm{CCl}_{4}$ activates the $2 \mathrm{E} 1$ isoform of cytochrome P450 (CYP2E1) and then forms highly reactive species $\mathrm{CCl}_{3} *$ and $\mathrm{CCl}_{3} \mathrm{OO}^{*}$ which initiates lipid peroxidation. Those reactive oxygen species (ROS) cause oxidative stress in the liver and attack several cellular targets, including endoplasmic reticulum, mitochondrial, and plasma membranes, which contribute to further cell damage. At the molecular level, $\mathrm{CCl}_{4}$ induces the expression of pro-inflammatory cytokines of tumor necrosis factor alpha (TNF- $\alpha$ ) and interleukin-1 beta (IL-1 $\beta$ ), which mediate the processes of apoptosis, inflammation, and fibrosis. On the other hand, treatment of $\mathrm{CCl}_{4}$ also activates transforming growth factors (TGF- $\alpha$ and TGF- $\beta$ ) which leads to the development of liver fibrosis [2]. 
Daily consumption of garlic and garlic-related products in several countries, including the United States, decreased the risk of colon and stomach cancer [3]. Previous research also revealed that $\mathrm{S}$-allylmercaptocysteine (SAMC), the naturally occurring water-soluble derivative of garlic, possesses anti-tumor properties in several cancers. In colon cancer cells, SAMC is shown to inhibit cell growth, arrest cell cycle, and induces apoptosis via depolymerizing microtubule, activate JNK1 and caspase-3 [4], as well as inactivating transcription factor NF- $\kappa \mathrm{B}$ [5]. In addition, in human gastric cancer cells, the anti-proliferative and proapoptosis effects of SAMC are associated with induction of caspase-3, caspase-9, p53, and Bax, rather than Bcl-2 and p21 [6]. In vivo study of androgen-independent prostate cancer model points out that SAMC suppresses metastasis via up-regulating cell adhesion molecules E-cadherin [7]. In rat cells and animal model, SAMC is also shown to play antioxidative effects in vitro and attenuates oxidative and nitrosative stresses in vivo [8]. In an acetaminopheninduced liver injury model, SAMC exerts its protective effects against hepatotoxicity by the inhibition of CYP2E1 enzymatic activity, leading to the suppression of acetaminophen arylation of hepatic proteins [9].

Although some efforts have been made to investigate the protection of SAMC in $\mathrm{CCl}_{4}$-induced liver damage [10], there is a lack of information on the molecular mechanisms of SAMC on such protection, especially on the attenuation of hepatic oxidative stress and inflammation. In the present study, we investigated the detailed molecular mechanisms of the protective role of $\mathrm{SAMC}$ in $\mathrm{CCl}_{4}$-induced acute hepatotoxicity, which may shed some light on the prevention of liver damage by taking SAMC as a supplement in the daily diet.

\section{Materials and methods}

\section{Reagents}

SAMC pure powder was a generous gift from Dr. Patrick M. T. Ling. It was dissolved in solvent buffer (10\% L-dextrose and $1 \%$ gum Arabic (w/v) in phosphate-buffered saline, $\mathrm{pH}$ 4.5). Carbon tetrachloride was purchased from Tianjin Baishi Chemical (Tianjin, China). Murine anti-nitrotyrosine monoclonal antibody was purchased from Zymed (San Francisco, CA). Rabbit anti-CYP2E1 and anti-I $\kappa \mathrm{B} \alpha$ polyclonal antibodies were purchased from Millipore (Billerica, MA) and Cell Signaling (Danvers, MA), respectively.

Animals and treatment

Eight- to ten-week healthy male and female C57BL/b6N mice were purchased from the Laboratory Animal Unit
(LAU), The University of Hong Kong. Mice were kept under standard conditions 1 week before $\mathrm{CCl}_{4}$ treatment with free access to animal chow and tap water. The animals were divided into four groups ( $n=8-10$ in each group): (1) control with vehicle administration (PBS or olive oil); (2) $\mathrm{CCl}_{4}$ single-dose treatment $(50 \mu \mathrm{l} / \mathrm{kg}$ in olive oil; intraperitoneal injection); (3) SAMC single-dose treatment (200 mg/kg in PBS; intraperitoneal injection); and (4) $\mathrm{CCl}_{4}$ and SAMC co-treatment. The optimum dosage of SAMC used was previously shown to be effective in protecting from oxidative stress in mice [11]. SAMC pre-treatment was performed $2 \mathrm{~h}$ before the $\mathrm{CCl}_{4}$ injection. After $8 \mathrm{~h}$ of $\mathrm{CCl}_{4}$ treatment, the mice were killed by an overdose of anesthesia according to the protocols approved by the Committee of Animal Use for Research and Teaching at The University of Hong Kong. The Laboratory Animal Unit of the University of Hong Kong is fully accredited by the Association for Assessment and Accreditation of Laboratory Animal Care International (AAALAC international). Blood and liver samples were collected for further analysis.

Tissue and blood samples processing and histopathological analysis

Serum were collected by centrifugation of whole blood sample at $1,000 \times g$ for $10 \mathrm{~min}$ at $4{ }^{\circ} \mathrm{C}$ and stored at $-80{ }^{\circ} \mathrm{C}$. Liver tissue samples were fixed in $10 \%$ phosphate-buffered formalin, processed for histology, and embedded in paraffin. Five-micrometer tissue sections were stained with hematoxylin and eosin for histological analysis under LEICA Qwin Image Analyser (Leica Microsystems Ltd., Milton Keynes, UK).

Serum alanine aminotransferase assay

The level of hepatic injury can be detected by the increased level of alanine aminotransferase (ALT) in the serum. The ALT assay was performed by procedures described previously [12].

RNA extraction and quantitative reverse-transcription polymerase chain reaction (real-time PCR)

Total RNA was extracted from the liver samples using illustra $^{\mathrm{TM}}$ RNAspin mini kit (GE healthcare, UK). The preparation of the first-strand cDNA was conducted following the instruction of the SuperScript ${ }^{\mathrm{TM}}$ First-Strand Synthesis System (Invitrogen, Calsbad, CA).

The mRNA expression levels of tumor necrosis factor alpha (TNF- $\alpha)$, interleukin- 1 beta (IL-1 $\beta$ ), inducible nitric oxide synthase (iNOS), cyclooxygenase-2 (COX-2), glutathione peroxidase (GPX), catalase (CAT), Cu/Zn SOD, 
monocyte chemoattractant protein-1 (MCP-1), macrophage inflammatory protein-2 (MIP-2), KC (murine IL-8 ortho$\log$ ), interleukin-6 (IL-6), and transforming growth factor beta1 (TGF- $\left.\beta_{1}\right)$ were measured by real-time PCR. The primers used in those real-time PCR reactions are listed in Table 1. The annealing temperature of each reaction has been adjusted to $58{ }^{\circ} \mathrm{C}$. Parallel amplification of glyceraldehyde-3-phosphate dehydrogenase (GAPDH) was used as the internal control. Relative quantification was performed using the $2^{-\Delta \Delta \mathrm{Ct}}$ method. The relative expression of the specific gene to the internal control was obtained and then expressed as percentage of the control expression in the Figures.

Determination of malondialdehyde level

The malondialdehyde (MDA) levels of liver samples were determined using a Bioxytech LPO-586 ${ }^{\mathrm{TM}}$ kit (Oxis Research, Portland, OR). The reaction product was measured spectrophotometrically at $586 \mathrm{~nm}$. Standard curves were constructed using 1,1,3,3-tetraethoxypropane as a

Table 1 Primer sequences for quantitative PCR

\begin{tabular}{|c|c|c|}
\hline $\begin{array}{l}\text { Target } \\
\text { gene }\end{array}$ & Direction & Sequence \\
\hline \multirow[t]{2}{*}{ TNF- $\alpha$} & Forward & 5'-ATGAGCACAGAAAGCATGATC-3' \\
\hline & Reverse & 5'-TACAGGCTTGTCACTCGAATT-3' \\
\hline \multirow[t]{2}{*}{$\mathrm{IL}-1 \beta$} & Forward & 5'-CAGGCAGGCAGTATCACTCA-3' \\
\hline & Reverse & $5^{\prime}$-AGGCCACAGGTATTTTGTCG-3' \\
\hline \multirow[t]{2}{*}{ iNOS } & Forward & 5'-GTGGTGACAAGCACATTTGG-3' \\
\hline & Reverse & 5'-GGCTGGACTTTTCACTCTGC-3' \\
\hline \multirow[t]{2}{*}{$\mathrm{COX}-2$} & Forward & 5'-GGAGAGACTATCAAGATAGTGATC3' \\
\hline & Reverse & 5'-ATGGTCAGTAGACTTTTACAGCTC-3' \\
\hline \multirow[t]{2}{*}{ GPx } & Forward & 5'-TCCACCGTGTATGCCTTCTCC-3' \\
\hline & Reverse & 5'-CCTGCTGTATCTGCGCACTGGA-3' \\
\hline \multirow[t]{2}{*}{ CAT } & Forward & 5'-GAGGCAGTGTACTGCAAGTTCC-3' \\
\hline & Reverse & 5'-GGGACAGTTCACAGGTATCTGC-3' \\
\hline \multirow[t]{2}{*}{$\mathrm{Cu} / \mathrm{Zn} \mathrm{SOD}$} & Forward & $5^{\prime}$-CGAGCAGAAGGCAAGC-3' \\
\hline & Reverse & $5^{\prime}$-GCCCAGGTCTCCAACA-3' \\
\hline \multirow[t]{2}{*}{ MCP-1 } & Forward & 5'-ACCAGCCAACTCTCACTGAAGC-3' \\
\hline & Reverse & 5'-CAGAATTGCTTGAGGTGGTTGTG-3' \\
\hline \multirow[t]{2}{*}{ MIP-2 } & Forward & 5'-AGTGAACTGCGCTCTCAATG-3' \\
\hline & Reverse & 5'-CTTTGGTTCTTCCGTTGAGG-3' \\
\hline \multirow[t]{2}{*}{$\mathrm{KC}$} & Forward & $5^{\prime}$-CTGTCAGTGCCTGCAGACCA-3' \\
\hline & Reverse & $5^{\prime}$-CCAAGGGAGCTTCAGGGTCA-3' \\
\hline \multirow[t]{2}{*}{ IL-6 } & Forward & $5^{\prime}$-CCGGAGAGGAGACTTCACAG-3' \\
\hline & Reverse & $5^{\prime}$-GGAAATTGGGGTAGGAAGGA-3' \\
\hline \multirow[t]{2}{*}{ TGF- $\beta_{1}$} & Forward & $5^{\prime}$-CTTCAGCTCCACAGAGAAGAACTGC- $3^{\prime}$ \\
\hline & Reverse & 5'-CACGATCATGTTGGACAACTGCTCC-3' \\
\hline \multirow[t]{2}{*}{ GAPDH } & Forward & 5'-CCTTCATTGACCTCAACTACATGGT-3' \\
\hline & Reverse & $5^{\prime}$-TCATTGTCATACCAGGAAATGAGCT-3' \\
\hline
\end{tabular}

standard. The MDA levels were normalized with corresponding protein amounts determined by Bio-Rad Protein Assay Kit (Bio-Rad, Hercules, CA) and represented as percentage against control level.

\section{Western blotting}

Protocols for cytosolic and nuclear protein extraction were previously described [12]. Protein was diluted and mixed with $2 \times$ sample buffer $(0.1 \mathrm{M}$ Tris- $\mathrm{HCl}, \mathrm{pH} 6.8$, $20 \%$ glycerol, $4 \%$ sodium dodecyl sulfate, $0.2 \%$ bromophenol blue, and $5.25 \% \beta$-mercaptoethanol). The mixture was denatured at $95{ }^{\circ} \mathrm{C}$ for $5 \mathrm{~min}$ and followed by electrophoresis in a $10 \%$ polyacrylamide gel. The protein was then transferred to an Immun-Blot ${ }^{\mathrm{TM}}$ PVDF Membrane (Bio-Rad) in a TE series transfer electrophoresis unit (Hoefer Inc., Holliston, MA). The membrane was then incubated in blocking buffer $(5 \%$ nonfat milk powder in TBST) for $1 \mathrm{~h}$ followed by incubation with primary antibodies (1:1,000 dilution for nitrotyrosine and $\mathrm{I} \kappa \mathrm{B} \alpha ; 1: 2,000$ dilution for CYP2E1) in TBST (100 mM Tris- $\mathrm{HCl}, \mathrm{pH} 7.5,0.9 \% \mathrm{NaCl}$, and $0.1 \%$ Tween 20) overnight at $4{ }^{\circ} \mathrm{C}$ with gentle agitation. On the following day, the membrane was washed with TBST and incubated with appropriate secondary antibodies (1:2,000 dilution in TBST) for $2 \mathrm{~h}$ at room temperature. Beta actin (Monoclonal; 1:5,000; Sigma, St. Louis, MO) was used as the internal control. After washing off the unbound antibody with TBST, the expression of the antibodylinked protein was determined by an $\mathrm{ECL}^{\mathrm{TM}}$ Western Blotting Detection Reagents (GE Healthcare). The optical density of the bands was measured and quantified by Image J software. The ratio of the optical density of the protein product to the internal control was obtained and was expressed as percentage of the control expression in the Figures.

Enzyme-linked immunosorbent assay measurement

Enzyme-linked immunosorbent assay (ELISA) measurements of IL- $1 \beta, \mathrm{KC}$, IL- 6 , and TGF- $\beta_{1}$ protein expression levels were performed using ELISA development kits from PeproTech (PeproTech Inc., Rocky Hill, NJ). ELISA of COX-2 was conducted using kit purchased from EIAab (Wuhan EIAab Science, Wuhan, China).

Determination of DNA-binding activity of nuclear factor- $\kappa \mathrm{B}$

The assay on the DNA-binding activity of nuclear factor$\kappa \mathrm{B}(\mathrm{NF}-\kappa \mathrm{B})$ was performed by electrophoretic mobility shift assay (EMSA) using the Gel Shift Assay Systems 
from Promega (Promega, Madison, WI). The assay was carried out following the protocol described previously [13]. Briefly, the phosphorylated and purified consensus NF- $\kappa$ B oligonucleotides (Promega) were mixed with $24 \mu \mathrm{g}$ of nuclear protein extract and $10 \times$ gel shift binding buffer $(200 \mathrm{~mm}$ Tris- $\mathrm{HCl}$, pH 7.8, $1 \mathrm{~m} \mathrm{NaCl}, 50 \mathrm{~mm}$ $\mathrm{MgCl}_{2}, 10 \mathrm{~mm}$ EDTA, and $50 \mathrm{~mm}$ dithiothreitol). The mixture was incubated at room temperature for $20 \mathrm{~min}$ prior to electrophoresis on a $4 \%$ non-denaturing polyacrylamide gel. Signals on exposed X-ray films were quantified using laser scanning densitometry. Specificity of NF- $\kappa \mathrm{B}$ binding was confirmed by competition assays and the ability of a specific antibody to supershift proteinDNA complexes. In the competition assay, the addition of 100-fold excess of unlabeled competitor consensus oligonucleotide prevented binding. Supershift experiments confirmed the presence of the p50 and p65 subunits in the binding complexes.

\section{Statistical analysis}

Data from each group were expressed as means \pm SEM. Statistical comparison between groups was made using the Kruskal-Wallis test followed by Dunns post hoc test to compare all groups. A $p<0.05$ was considered to be statistically significant (Prism 5.0, Graphpad software, Inc., San Diego, CA, USA).

\section{Results}

$\mathrm{CCl}_{4}$ treatment induced hepatocyte necrosis and inflammation surrounding the centrilobular veins of the liver which were obviously attenuated by the pre-treatment of SAMC (Fig. 1a-d). It should be noted that SAMC injection alone did not show any histological change in the liver (Fig. 1c). Serum ALT level of $\mathrm{CCl}_{4}$-treated mice was approximately 3.5 -fold higher than that of the control group. Pre-treatment of SAMC also significantly reduced the expression of serum ALT induced by $\mathrm{CCl}_{4}$ to the control-like level. SAMC treatment alone did not change the baseline level of serum ALT (Fig. 1e; $p<0.05$ ). Previous studies have shown that the isoform $2 \mathrm{E} 1$ of cytochrome P450 (CYP2E1) is transiently down-regulated in the early stage of $\mathrm{CCl}_{4}$ administration as a self-defense mechanism [14]. In the present study, protein expression of CYP2E1 was also reduced after $\mathrm{CCl}_{4}$ treatment to approximately $50 \%$ of that in the control group. Treatment of SAMC alone also led to a significant decrease in CYP2E1 expression which was around $70 \%$ of the control level. Levels were further reduced in SAMC and $\mathrm{CCl}_{4}$ co-treatment mice when compared with the control group (Fig. 2a; $p<0.05$ ).
The mRNA levels of antioxidant enzymes GPx, CAT, and $\mathrm{Cu} / \mathrm{Zn}$ SOD were significantly reduced in $\mathrm{CCl}_{4}$ treatment group when compared with the control group. The mice pre-treated with SAMC followed by $\mathrm{CCl}_{4}$ injection exhibited similar expression levels of these antioxidant enzymes as the control group (Fig. 2b-d).

To investigate the effect of SAMC on hepatic lipid peroxidation, levels of hepatic malondialdehyde (MDA) were measured after $\mathrm{CCl}_{4}$ with or without SAMC pretreatment. When compared with the control group, mice treated with $\mathrm{CCl}_{4}$ alone showed approximately 3.5-fold increases in the MDA level. However, pre-treatment with SAMC significantly reduced the MDA level (Fig. 3a). Although SAMC treatment alone also slightly increased the MDA level, the ameliorative effect of SAMC on hepatic lipid peroxidation is obvious.

As an indicator of cellular oxidative stress and inflammation, the formation of nitrotyrosine was highly elevated (around 1.7-fold than control level) after $\mathrm{CCl}_{4}$ treatment. However, when compared with the $\mathrm{CCl}_{4}$ group, mice pretreated with $\mathrm{SAMC}$ followed by $\mathrm{CCl}_{4}$ showed a significant reduction in nitrotyrosine formation, which was comparable with the control group (Fig. 3b).

After $\mathrm{CCl}_{4}$ treatment, the mRNA expressions of proinflammatory factors TNF- $\alpha$, iNOS, IL- $1 \beta$, and COX-2 were increased by approximately $3.4,1.6,1.7$, and 4.1 -fold, respectively, when compared with the control group. In the pre-treatment with SAMC followed by $\mathrm{CCl}_{4}$ group, the mRNA expression levels of TNF- $\alpha$, iNOS, and IL- $1 \beta$ were markedly decreased to the basal levels (Fig. 4a-c). Pretreatment with SAMC followed by $\mathrm{CCl}_{4}$ also markedly reduced the COX-2 mRNA expression when compared with the $\mathrm{CCl}_{4}$ group, although to a level not as low as the control group (Fig. 4e). Protein expression levels of IL-1 $\beta$ and COX-2 confirmed the trends observed in mRNA results (Fig. 4d, f).

Since the expressions of chemokines in the liver were up-regulated by cytokines, oxidative products, and growth factors during inflammation, the change in expression level and distribution becomes an indicative parameter of hepatic inflammation and oxidation [15]. After $\mathrm{CCl}_{4}$ challenge, mRNA expressions of monocyte chemoattractant protein-1 (MCP-1, CCL2), macrophage inflammatory protein-2 (MIP-2, CXCL3), and murine KC (IL-8 ortholog, CXCL1) increased by $8,4.5$, and 1.7 -fold, respectively, when compared with the control group, but significantly reduced in the SAMC and $\mathrm{CCl}_{4}$ treatment group (Fig. 5ac). ELISA assay of KC protein expression showed similar patterns corresponding to its mRNA expression, further confirming the effect of SAMC on chemokine expressions (Fig. 5d).

To investigate the effect of SAMC on hepatic regeneration, we measured the expressions of IL- 6 and TGF- $\beta 1$, 
Fig. 1 Protective effects of SAMC against $\mathrm{CCl}_{4}$-induced hepatotoxicity. H\&E staining on a control, b $\mathrm{CCl}_{4}$ treatment, c SAMC treatment, and d $\mathrm{CCl}_{4}+\mathrm{SAMC}$ groups. $\mathrm{CCl}_{4}$ treatment caused obvious centrilobular necrosis in the liver. However, no significant necrosis and inflammation are observed in control, SAMC treatment, and $\mathrm{CCl}_{4}+\mathrm{SAMC}$ groups. e $\mathrm{CCl}_{4}$ exposure induced an increase in serum ALT level which was reversed by the pre-treatment of SAMC. Data presented are expressed as Mean \pm SEM $(n=8-10)$ and experimental groups marked by different letters represented significant differences between groups at $p<0.05$ (KruskalWallis test followed by Dunns post hoc test). Bar equals 20 microns
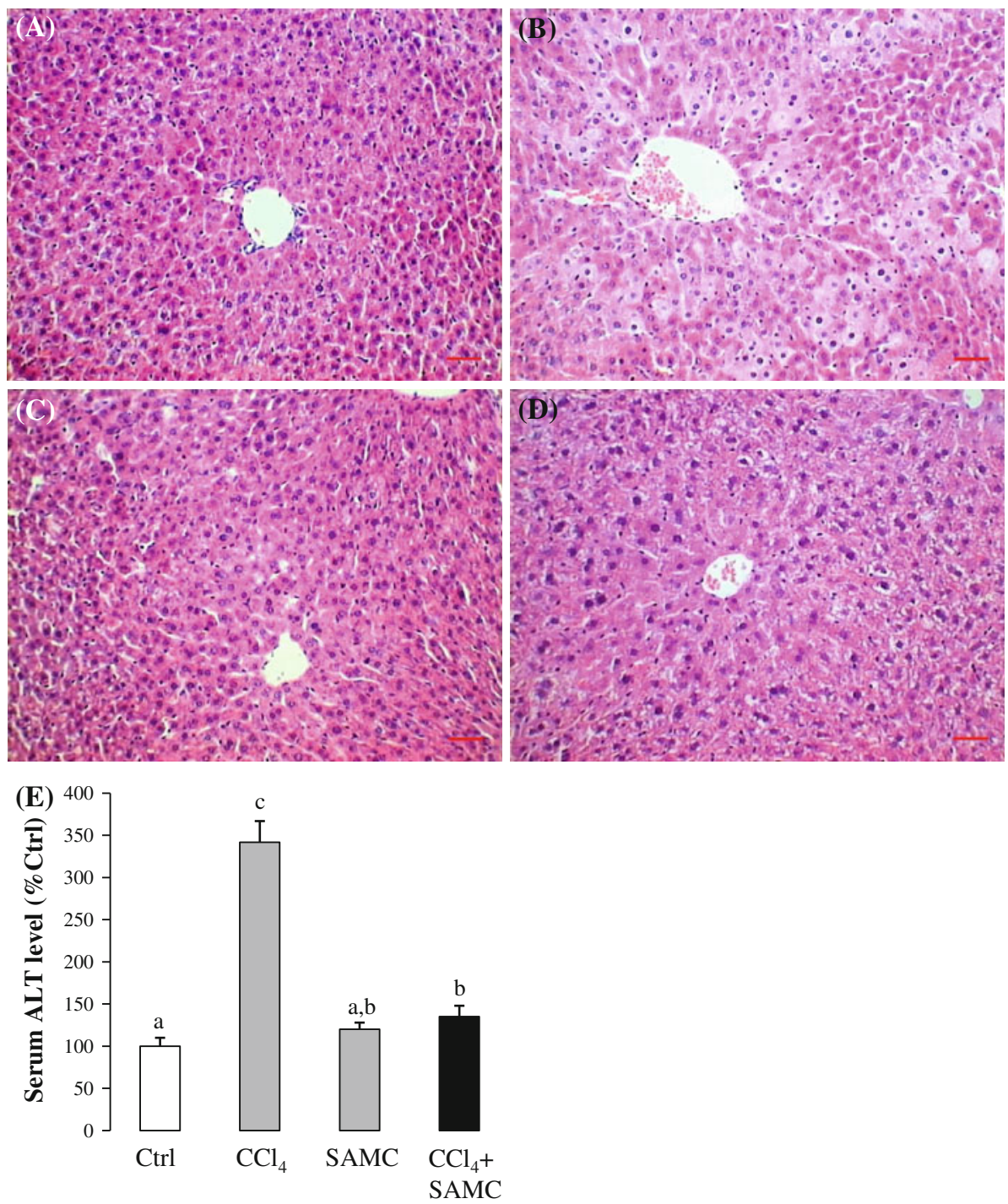

which are key genes involved in the processes of regeneration, anti-inflammation, and fibrosis. $\mathrm{CCl}_{4}$ challenge significantly up-regulated the expression of these two genes, and the group treated with SAMC and $\mathrm{CCl}_{4}$ potentiated such elevated expression (Fig. 6a, c). Protein expression of IL- 6 confirmed the trend of its mRNA expression (Fig. 6b).

Acute $\mathrm{CCl}_{4}$ treatment markedly up-regulated the activity level of NF- $\kappa \mathrm{B}$ to approximately 2.5 -fold of the control. Pre-treatment with SAMC followed by $\mathrm{CCl}_{4}$ showed a significant reduction in the activity of NF- $\kappa \mathrm{B}$ when compared with the control group. Moreover, cytosolic content of $\mathrm{I} \kappa \mathrm{B} \alpha$ was significantly decreased by $\mathrm{CCl}_{4}$ treatment but restored by the pre-treatment of SAMC (Fig. 7a). Supershift assay of p50 and p65 antibodies showed a lighter intensity and a slight upward retarded shift of the NF- $\kappa \mathrm{B}$ band confirming the specificity of the reactions in the gel shift assay (Fig. 7b).

\section{Discussion}

$\mathrm{CCl}_{4}$ was proven to be a useful experimental model for hepatotoxicity studies, although banned for industrial and home use as cleaner and solvent [16]. A huge number of natural products, mainly originating from traditional Asian medicine, have been tested recently for the protective effects against $\mathrm{CCl}_{4}$-induced toxicity such as vitamin $\mathrm{E}$ [17], green tea extracts [18], ginsan [19], coffee [20], and even mushroom [21]. Because of the similarities in the mechanism of actions, these protective agents also have the potential to be used in the treatment of AFLD (alcoholic fatty liver disease), NAFLD (non-alcoholic fatty liver disease), and cirrhosis [22, 23]. Sumioka et al. showed that in overdose acetaminophen-induced liver injury model, SAMC protected liver from drug-induced damage by inhibiting CYP2E1 and inducing a biomarker of acetaminophen arylation of liver protein [9]. In the present study, 
Fig. 2 Antioxidative properties of SAMC. Expression levels of a CYP2E1 protein, b GPX mRNA, c CAT mRNA, and d $\mathrm{Cu} / \mathrm{Zn}$ SOD mRNA were measured in mice liver after $\mathrm{CCl}_{4}$ with or without pretreatment of SAMC. GAPDH and $\beta$-actin were used as internal controls for target gene's mRNA and protein expression, respectively. Data presented are expressed as Mean \pm SEM $(n=8-10)$ and experimental groups marked by different letters represented significant differences between groups at $p<0.05$ (KruskalWallis test followed by Dunns post hoc test)
(A)

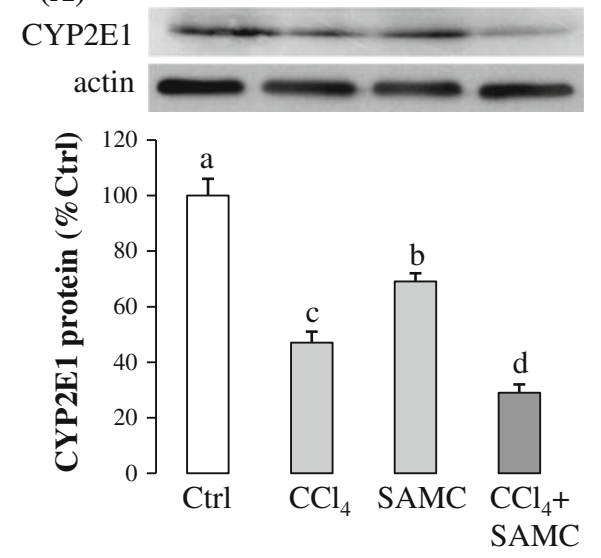

(B)

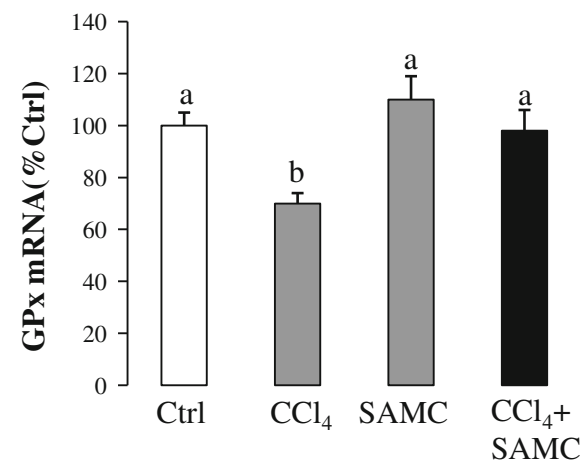

(D)

(C)

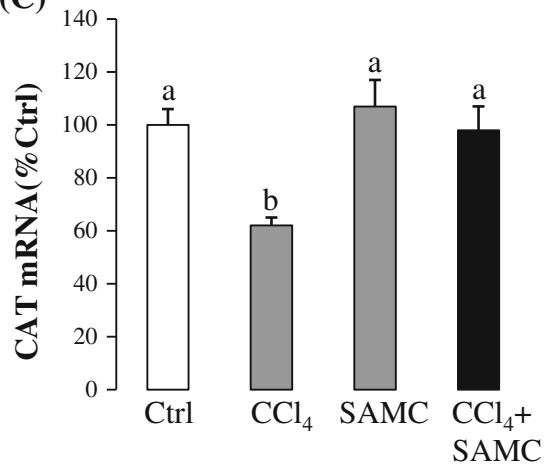

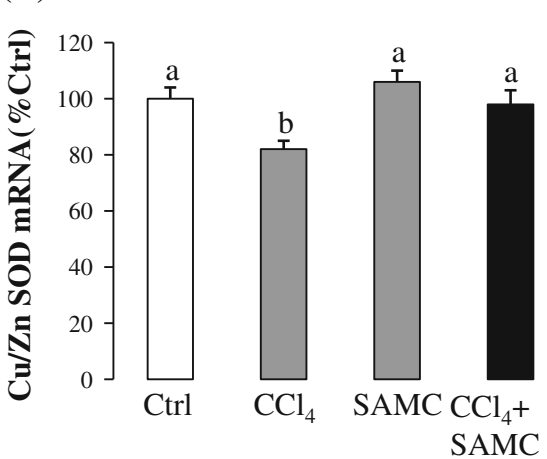

we demonstrated that administration of SAMC protected $\mathrm{CCl}_{4}$-induced acute liver injury through different mechanisms, including the inhibition of CYP2E1, down-regulation of inflammatory mediators and nuclear transcription factor, restoration of intracellular antioxidant enzymes, and promotion of liver regeneration, which added to the novel mechanistic aspects of the known beneficial properties of SAMC.

As an indicative enzyme, ALT is normally contained within liver cells. After cellular damage, the enzyme is released into the bloodstream and raising the blood ALT enzyme level, suggesting the presence of liver damage [24]. In the present study, $\mathrm{CCl}_{4}$ treatment dramatically increased the serum ALT level, induced hepatic centrilobular necrosis, and increased the number of inflammatory cells surrounding the centrilobular veins. We found that pre-treatment with SAMC significantly decreased the serum ALT biomarker as well as ameliorated hepatocellular injury against $\mathrm{CCl}_{4}$ without affecting the healthy cells (Fig. 1).

Through the actions of the cytochrome $\mathrm{P} 450$ oxygenase system within the endoplasmic reticulum, mainly the isozyme of CYP2E1, the $\mathrm{CCl}_{3}$ * radical is formed by the metabolism of $\mathrm{CCl}_{4}$. In the presence of oxygen/hydrogen,
$\mathrm{CCl}_{3} *$ may convert to $\mathrm{CCl}_{3} \mathrm{OO} *$ /chloroform to attack many targets including DNA, amino acid, and proteins. $\mathrm{CCl}_{3} \mathrm{OO} *$ can also abstract a hydrogen to form polyunsaturated fatty acid (PUFA), initiating lipid peroxidation [2]. In a previous study, it was shown that the expression of CYP2E1 was down-regulated after $\mathrm{CCl}_{4}$ intoxication as an adaptive mechanism to limit hepatotoxicity. In addition, restoration of CYP2E1 expression or stabilization of this enzyme made $\mathrm{CCl}_{4}$-induced injury more severe [14]. This finding was further confirmed by a protective assay of ginsan, which is an antioxidant compound from plant, in $\mathrm{CCl}_{4}$ induced hepatic injury model [19]. In this study, SAMC potentiated the down-regulation of CYP2E1 expression induced by $\mathrm{CCl}_{4}$. Moreover, SAMC further demonstrated its protective properties by attenuating $\mathrm{CCl}_{4}$-induced oxidative stress through the reduction in nitrotyrosine formation and MDA, the end-products of nitric oxide (NO) and lipid peroxidation, respectively (Fig. 3). In the present study, we further investigated the expression of several hepatic antioxidant enzymes after $\mathrm{CCl}_{4}$ challenge. $\mathrm{CCl}_{4}$ treatment alone significantly decreased the mRNA expressions of GPx, CAT, and $\mathrm{Cu} / \mathrm{Zn}$ SOD, whereas pretreatment with SAMC followed by $\mathrm{CCl}_{4}$ had the expressions of those enzymes similar to baseline levels (Fig. 2). 
(A)

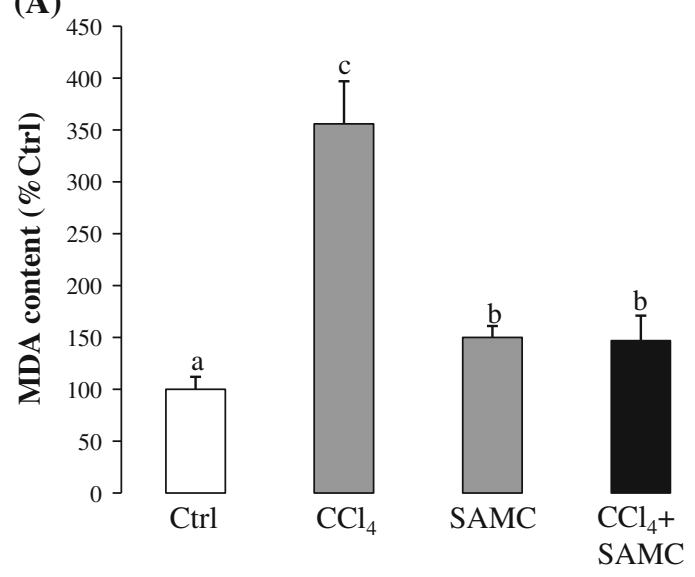

(B)
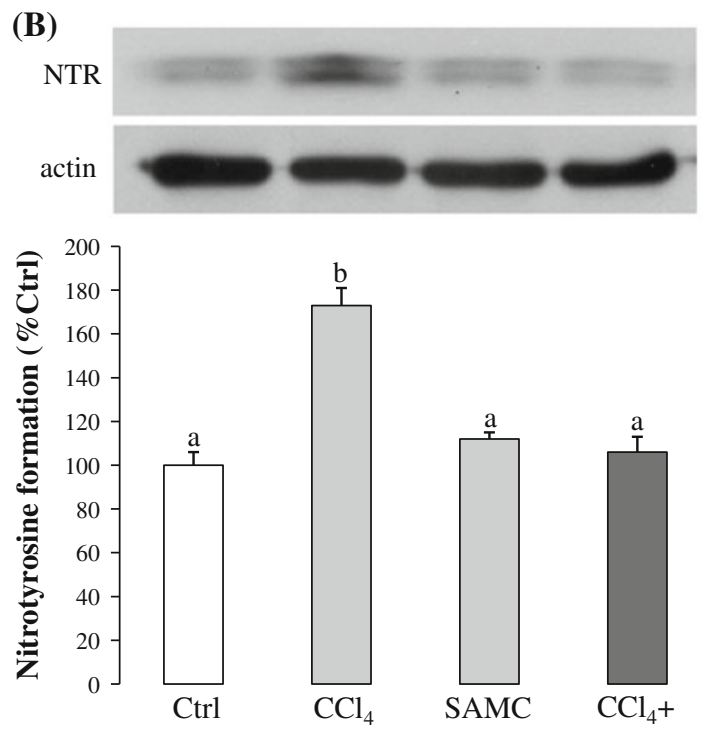

Fig. 3 Ameliorative properties of SAMC on lipid peroxidation and NO metabolism. Formation of $\mathbf{a}$ MDA and $\mathbf{b}$ nitrotyrosine was measured in mice liver after $\mathrm{CCl}_{4}$ with or without pre-treatment of SAMC. $\beta$-actin was used as internal control for the formation of nitrotyrosine. Data presented are expressed as Mean \pm SEM $(n=8-10)$ and experimental groups marked by different letters represented significant differences between groups at $p<0.05$ (Kruskal-Wallis test followed by Dunns post hoc test)

Since $\mathrm{Cu} / \mathrm{Zn}$ SOD is the main antioxidant which dismutate $\mathrm{O}_{2}^{--}$into $\mathrm{H}_{2} \mathrm{O}_{2}$ and CAT/GPx are enzymes which degrade $\mathrm{H}_{2} \mathrm{O}_{2}$ [25], these findings are consistent with results seen in the nitrotyrosine and MDA assays, further lending more support to the antioxidative effect of SAMC in mice. Taking all findings together, SAMC protected $\mathrm{CCl}_{4^{-}}$ induced oxidative stress at different mechanisms.

To further study the mechanism of the protective roles of SAMC, we measured the expressions of inflammatory mediators after $\mathrm{CCl}_{4}$ treatment. It has been reported that hepatic inflammatory responses are initiated as early as $30 \mathrm{~min}$ after $\mathrm{CCl}_{4}$ exposure [2]. Pro-inflammatory cytokines, TNF- $\alpha$, and IL-1 $\beta$ are released from Kupffer cells, the resident macrophages in the liver [26]. When cellular RNA and protein synthesis are repressed by $\mathrm{CCl}_{4}$ exposure, hepatocytes becomes sensitized to TNF- $\alpha$, which induces the activity of transcription factors NF- $\kappa \mathrm{B}, \mathrm{AP}-1$, and STAT-3 [27]. Normally, TNF- $\alpha$ suppresses hepatocellular apoptosis or even to affect recovery through its conjugate receptor TNFR1 and another family member of interleukin, IL-6 [28]. However, when $\mathrm{CCl}_{4}$ inhibits cellular protein synthesis, this cytokine becomes a pro-apoptotic factor which potentiates the apoptotic signaling cascade from ROS-damaged mitochondria [29]. Similar to $\mathrm{TNF}-\alpha$, when associated with oxidative stress induced by $\mathrm{CCl}_{4}$, IL-1 $\beta$ also triggers cellular necrosis and apoptosis pathways by changing the balance of ligand and receptor $[30,31]$. Moreover, elevated expression of TNF- $\alpha$ and IL-1 $\beta$ also stimulates the production of NO, a highly reactive oxidant molecule produced by both parenchymal and non-parenchymal liver cells via iNOS [32]. In the current study, SAMC greatly reduced the expression levels of pro-inflammatory mediators induced by $\mathrm{CCl}_{4}$ exposure at both transcriptional and translational level, confirming its protective role against $\mathrm{CCl}_{4}$. Since pre-treatment with SAMC also decreased the protein level of NO metabolic product nitrotyrosine, it could be suggested that the inhibition of pro-inflammatory cytokines and the restoration of antioxidant enzymes during SAMC pre-treatment followed by $\mathrm{CCl}_{4}$ intoxication not only prevented cellular necrosis and apoptosis, but also repressed the positive-feedback loop between inflammation, lipid peroxidation, and oxidative stress.

Up-regulation of chemokines in the liver is a part of the inflammation response to haloalkane intoxication, e.g., $\mathrm{CCl}_{4}$, via controlling migration and recruitment of both the inflammatory Kupffer cells and the non-inflammatory stellate cells [15]. Since MCP-1 [33], MIP-2 [34], and KC (mouse IL-8 otholog) [35] are induced by cytokines (e.g., TNF- $\alpha$ ) in the inflammatory microenvironment, we tested the effects of SAMC pre-treatment on their expressions after $\mathrm{CCl}_{4}$ exposure. Both mRNA and protein levels of these chemokines were significantly down-regulated by the pre-treatment of SAMC followed by $\mathrm{CCl}_{4}$, which demonstrated that the anti-inflammation property of SAMC was involved in the regulation of both the inflammatory factors and chemokines.

As an acute phase response factor, IL-6 antagonizes $\mathrm{TNF} \alpha$-induced inflammation and stabilizes cell membranes after $\mathrm{CCl}_{4}$ treatment, protecting cells from oxidative stress [27]. IL-6 also binds to both membrane-bound IL-6 receptor and soluble IL-6 receptor to trigger NF- $\kappa \mathrm{B}-$ and STAT3-dependent hepatic regeneration $[36,37]$. TGF- $\beta_{1}$ is mainly a pro-fibrotic factor in chronic liver disease, e.g., fatty liver disease. However, a recent study also found its 
Fig. 4 Anti-inflammatory properties of SAMC.

Expression levels of a TNF- $\alpha$ mRNA, b iNOS mRNA, $\mathbf{c}$ IL- $1 \beta$ mRNA, d IL- $1 \beta$ protein, e COX-2 mRNA, and f COX-2 protein were measured in mice liver after $\mathrm{CCl}_{4}$ with or without pre-treatment of SAMC.

GAPDH was used as internal controls for target gene's mRNA expression. Data presented are expressed as Mean \pm SEM $(n=8-10)$ and experimental groups marked by different letters represented significant differences between groups at $p<0.05$ (KruskalWallis test followed by Dunns post hoc test)
(A)

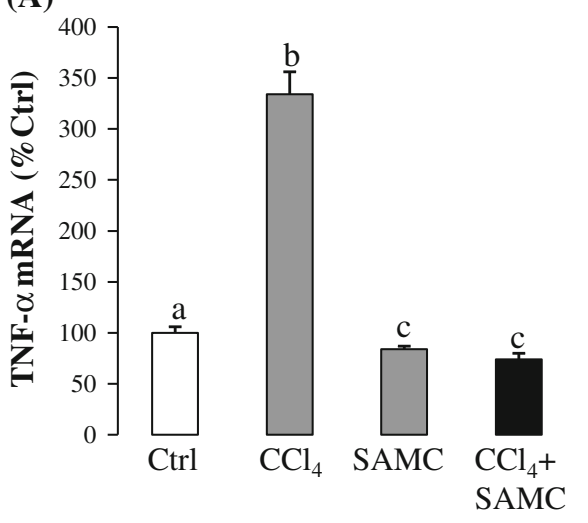

(C)

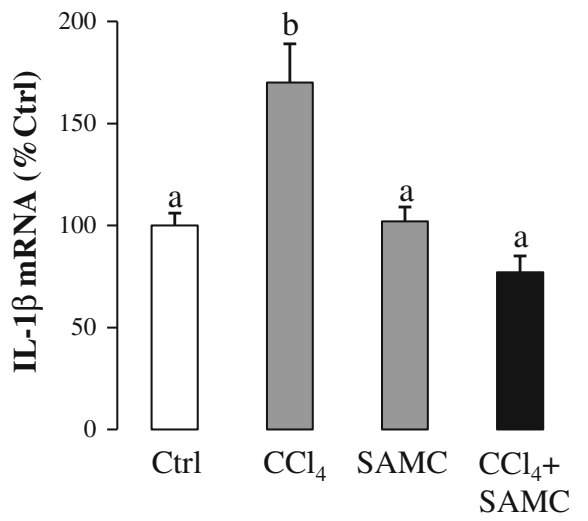

(E)

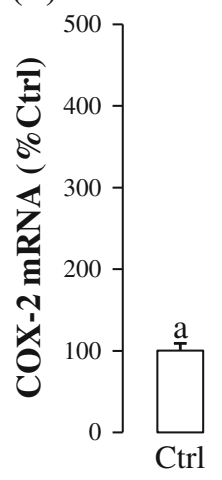

(B)

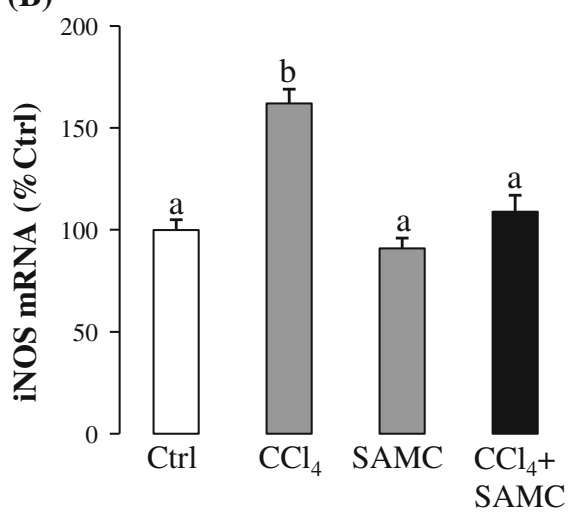

(D)

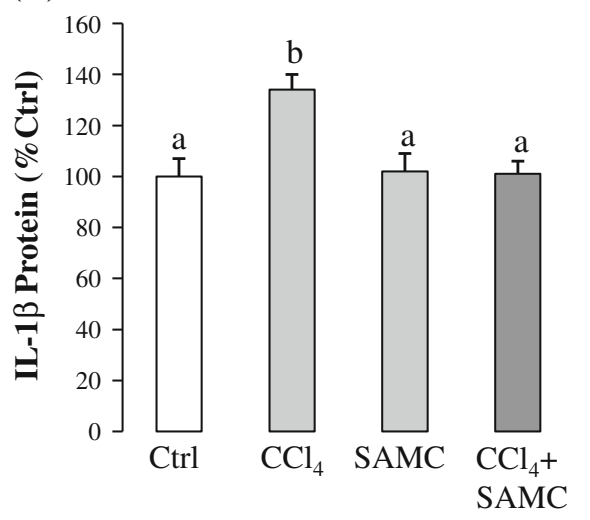

(F)

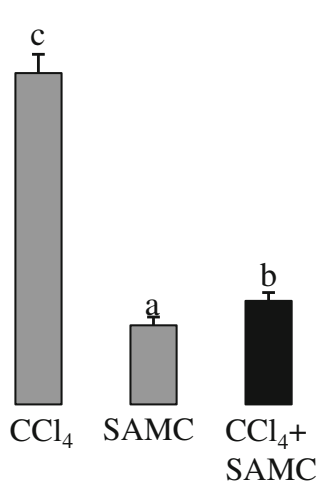

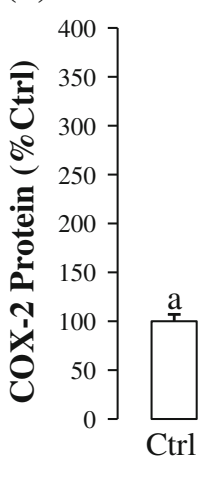

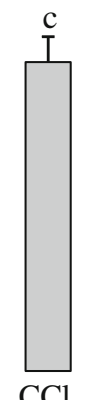

$\mathrm{CCl}_{4} \quad \mathrm{SAMC}$ b

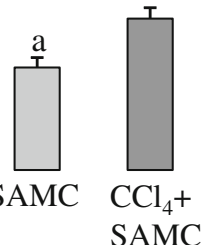

role in promoting hepatic remodeling during the process of liver regeneration through increasing the expression of a cell adhesion molecule known as gicerin [38]. In the present study, SAMC potentiated the induced IL- 6 and TGF- $\beta_{1}$ expressions after $\mathrm{CCl}_{4}$ treatment, suggesting the pro-regenerative and the anti-inflammatory properties in SAMC during the early phase of $\mathrm{CCl}_{4}$ intoxication. This finding is consistent with other reported studies using different antioxidants [19].

When an intermediate amount of ROS is generated by $\mathrm{CCl}_{4}$ exposure, transcription factors (e.g., NF- $\kappa \mathrm{B}$ and
AP-1) are activated and translocated into the nucleus. $\mathrm{NF}-\kappa \mathrm{B}$ and AP-1 then promote the transcription of more inflammatory cytokines and chemokines which form a positive-feedback loop to potentiate the inflammatory response $[39,40]$. Moreover, $\mathrm{H}_{2} \mathrm{O}_{2}$ and $\mathrm{NO}$ formed during $\mathrm{CCl}_{4}$ intoxication also directly modulate NF- $\kappa \mathrm{B}$ activation via an IKK-dependent degradation of $\mathrm{I} \kappa \mathrm{B} \alpha$ pathway, making this transcription factor a central regulatory molecule in regulating $\mathrm{CCl}_{4}$-induced oxidation and inflammation $[41,42]$. In the current study, administration of SAMC prior to $\mathrm{CCl}_{4}$ challenge significantly reduced the NF- $\kappa \mathrm{B}$ 
Fig. 5 Attenuation of chemokine expression by SAMC. Expression levels of a MCP-1 mRNA, b MIP-2 mRNA, $\mathbf{c}$ KC mRNA, and $\mathbf{d} \mathrm{KC}$ protein were measured in mice liver after $\mathrm{CCl}_{4}$ with or without pre-treatment of SAMC.

GAPDH was used as internal controls for target gene's mRNA expression. Data presented are expressed as Mean \pm SEM $(n=8-10)$ and experimental groups marked by different letters represented significant differences between groups at $p<0.05$ (KruskalWallis test followed by Dunns post hoc test)

Fig. 6 Pro-regenerative effect of SAMC. Expression levels of a IL-6 mRNA, b IL-6 protein, c TGF- $\beta_{1}$ mRNA, and d TGF- $\beta_{1}$ protein were measured in mice liver after $\mathrm{CCl}_{4}$ with or without co-treatment of SAMC.

GAPDH was used as internal controls for target gene's mRNA expression. Data presented are expressed as Mean \pm SEM $(n=8-10)$ and experimental groups marked by different letters represented significant differences between groups at $p<0.05$ (KruskalWallis test followed by Dunns post hoc test)
(A)
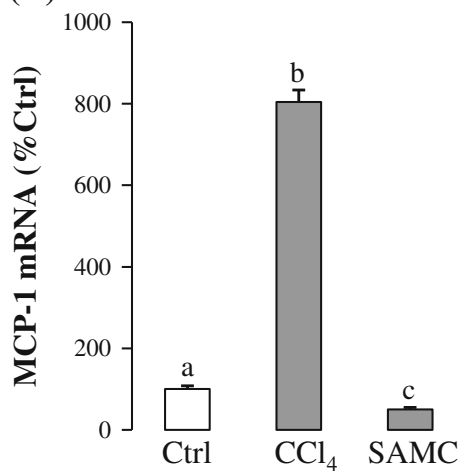

(C)

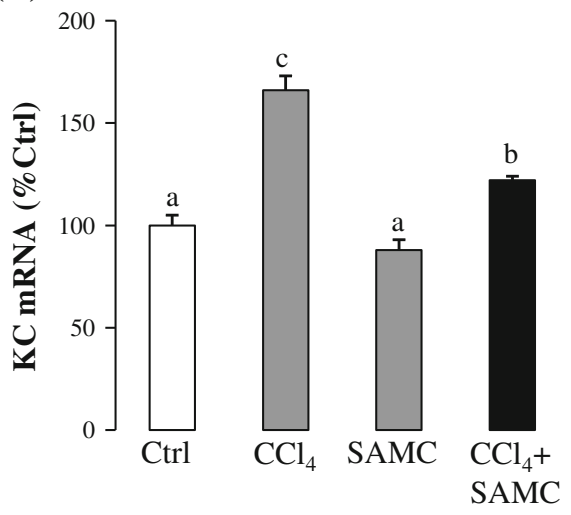

(A)

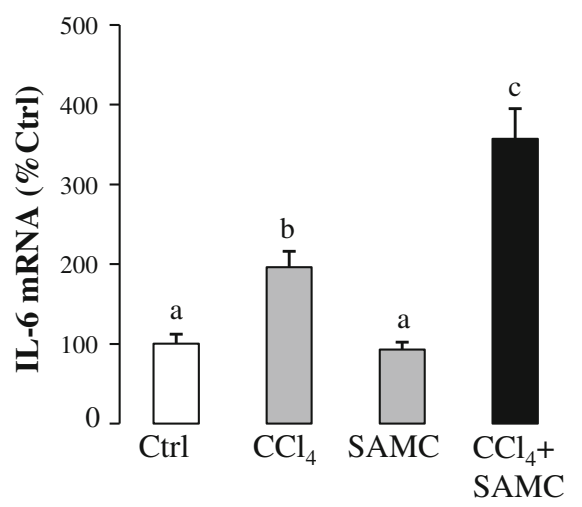

(C)

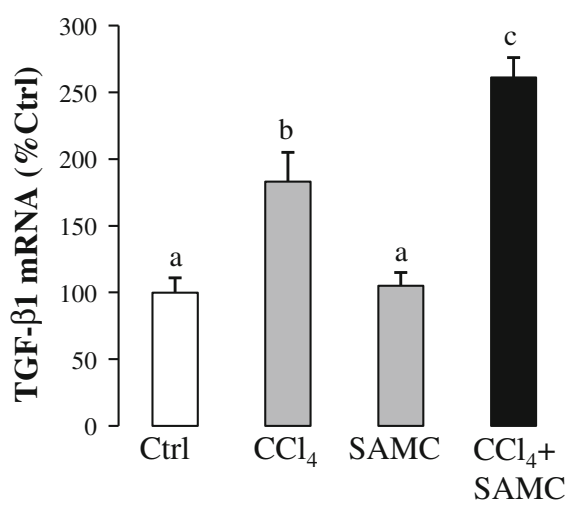

(B)

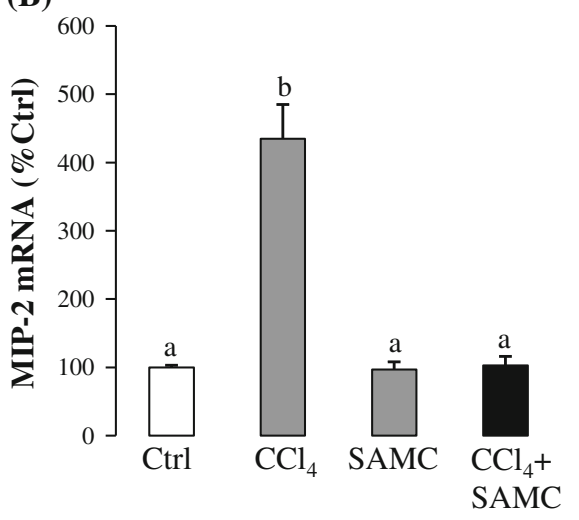

(D)

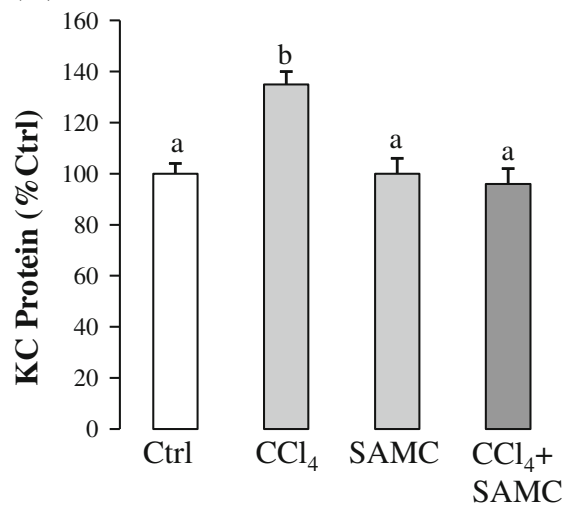

(B)

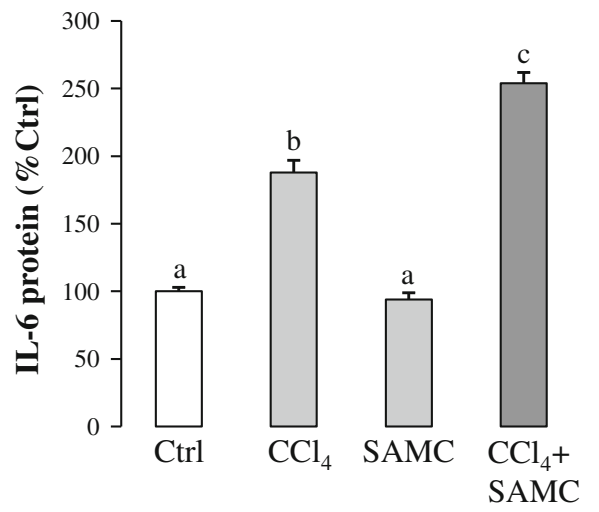

(D)

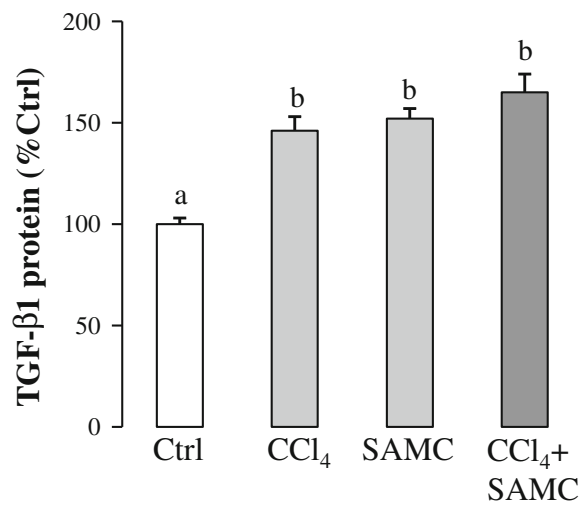


(A)

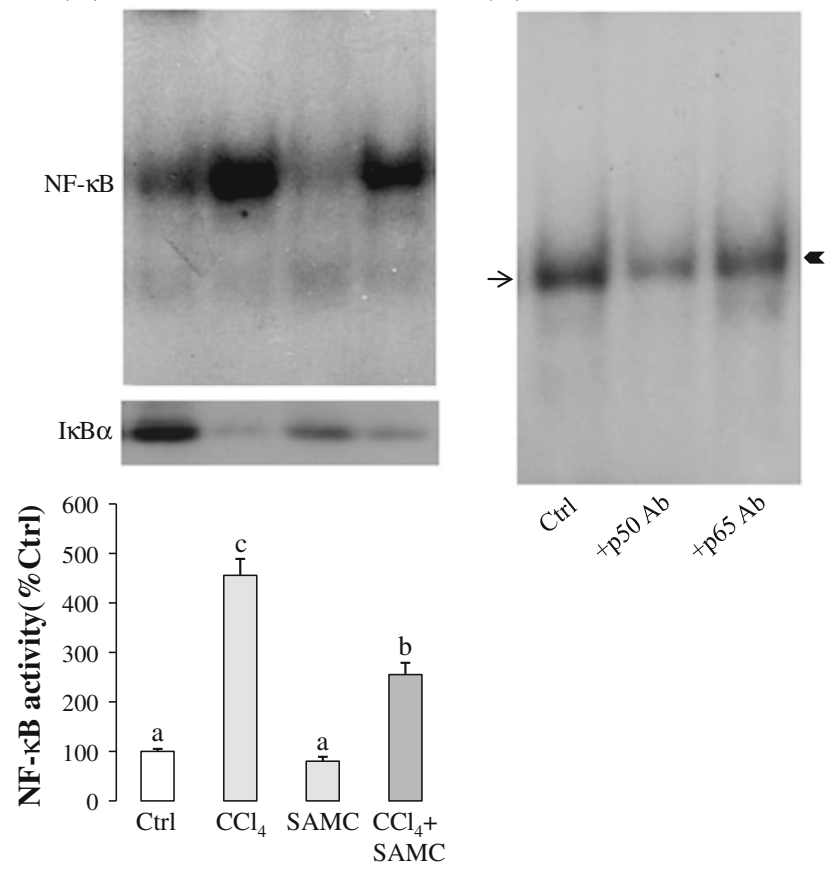

Fig. 7 DNA-binding activity of NF- $\kappa \mathrm{B}$ modulated by $\mathrm{CCl}_{4}$ and SAMC. a Gel shift assay. In $\mathrm{CCl}_{4}$-treated group, the activity level of $\mathrm{NF}-\kappa \mathrm{B}$ (p50 and p65) was significantly increased. Treatment with SAMC markedly reduced the activity level without disturbing the basal activity. In cytoplasm, $\mathrm{CCl}_{4}$ treatment stimulated the degradation of $\mathrm{I} \kappa \mathrm{B} \alpha$. Pre-treatment of SAMC partially restored the expression of $\mathrm{I} \kappa \mathrm{B} \alpha$. b Supershift assay conducted with monoclonal p50 and p65 antibodies to test the involvement of these subunits in the gel shift assay. Arrow indicates DNA-NF- $\kappa$ B complex. Arrowhead indicates shifted DNA-NF- $\kappa$ B band. Data presented are expressed as Mean \pm SEM $(n=8-10)$ and experimental groups marked by different letters represented significant differences between groups at $p<0.05$ (Kruskal-Wallis test followed by Dunns post hoc test)

activity through the degradation of cytosolic $\mathrm{I} \kappa \mathrm{B} \alpha$. Thus, SAMC may ameliorate both oxidative stress and inflammatory signaling through regulation in the activity of the transcription factor NF- $\kappa \mathrm{B}$.

In conclusion, this study showed that the administration of garlic-derived SAMC was effective in ameliorating $\mathrm{CCl}_{4}$-induced hepatotoxicity through the regulation of oxidative stress, inflammatory signaling, and liver regeneration in association with the reduction in the activity of the transcription factor NF- $\kappa$ B. Since AFLD, NAFLD, and other xenobiotics share a similar mechanism in liver damage with the $\mathrm{CCl}_{4}$ intoxication model, the hepatoprotective properties of SAMC are of significant clinical application in the prevention and treatment of chronic liver diseases. Compared with other antioxidant agents reported recently, garlic is easier to purchase and in an abundant supply, so it could be used as a daily food supplement which may prevent the onset of liver injury.
Acknowledgments We would like to thank Ms. Carman Leung for her technical help in this project. This study is partly supported by Small Project Funding, University Research Committee, The University of Hong Kong and General Research Fund, University Grant Council, Hong Kong SAR.

\section{Conflict of interest None.}

Open Access This article is distributed under the terms of the Creative Commons Attribution Noncommercial License which permits any noncommercial use, distribution, and reproduction in any medium, provided the original author(s) and source are credited.

\section{References}

1. Muriel P (1998) Nitric oxide protection of rat liver from lipid peroxidation, collagen accumulation, and liver damage induced by carbon tetrachloride. Biochem Pharmacol 56:773-779

2. Weber LW, Boll M, Stampfl A (2003) Hepatotoxicity and mechanism of action of haloalkanes: carbon tetrachloride as a toxicological model. Crit Rev Toxicol 33:105-136. doi:10.1080/ 713611034

3. Fleischauer AT, Arab L (2001) Garlic and cancer: a critical review of the epidemiologic literature. J Nutr 131:1032S-1040S

4. Xiao D, Pinto JT, Soh JW, Deguchi A, Gundersen GG, Palazzo AF, Yoon JT, Shirin H, Weinstein IB (2003) Induction of apoptosis by the garlic-derived compound S-allylmercaptocysteine (SAMC) is associated with microtubule depolymerization and c-Jun $\mathrm{NH}(2)$-terminal kinase 1 activation. Cancer Res 63:6825-6837

5. Ban JO, Yuk DY, Woo KS, Kim TM, Lee US, Jeong HS, Kim DJ, Chung YB, Hwang BY, Oh KW, Hong JT (2007) Inhibition of cell growth and induction of apoptosis via inactivation of NF-kappaB by a sulfur compound isolated from garlic in human colon cancer cells. J Pharmacol Sci 104:374-383

6. Lee Y (2008) Induction of apoptosis by S-allylmercapto-L-cysteine, a biotransformed garlic derivative, on a human gastric cancer cell line. Int J Mol Med 21:765-770

7. Howard EW, Ling MT, Chua CW, Cheung HW, Wang X, Wong YC (2007) Garlic-derived S-allylmercaptocysteine is a novel in vivo antimetastatic agent for androgen-independent prostate cancer. Clin Cancer Res 13:1847-1856. doi:10.1158/1078-0432. CCR-06-2074

8. Pedraza-Chaverri J, Barrera D, Maldonado PD, Chirino YI, MaciasRuvalcaba NA, Medina-Campos ON, Castro L, Salcedo MI, Hernandez-Pando R (2004) S-allylmercaptocysteine scavenges hydroxyl radical and singlet oxygen in vitro and attenuates gentamicin-induced oxidative and nitrosative stress and renal damage in vivo. BMC Clin Pharmacol 4:5. doi:10.1186/1472-6904-4-5

9. Sumioka I, Matsura T, Yamada K (2001) Therapeutic effect of S-allylmercaptocysteine on acetaminophen-induced liver injury in mice. Eur J Pharmacol 433:177-185

10. Nakagawat S, Kasuga S, Matsuura H (1989) Prevention of liver damage by aged garlic extract and its components in mice. Phytother Res 3:50-53. doi:10.1002/ptr.2650030203

11. Sumioka I, Matsura T, Kasuga S, Itakura Y, Yamada K (1998) Mechanisms of protection by S-allylmercaptocysteine against acetaminophen-induced liver injury in mice. Jpn J Pharmacol 78:199-207

12. Tipoe GL, Leung TM, Hung MW, Fung ML (2007) Green tea polyphenols as an anti-oxidant and anti-inflammatory agent for cardiovascular protection. Cardiovasc Hematol Disord Drug Target 7:135-144 
13. Leung TM, Tipoe GL, Liong EC, Lau TY, Fung ML, Nanji AA (2008) Endothelial nitric oxide synthase is a critical factor in experimental liver fibrosis. Int J Exp Pathol 89:241-250. doi: 10.1111/j.1365-2613.2008.00590.x

14. Taieb D, Malicet C, Garcia S, Rocchi P, Arnaud C, Dagorn JC, Iovanna JL, Vasseur S (2005) Inactivation of stress protein $\mathrm{p} 8$ increases murine carbon tetrachloride hepatotoxicity via preserved CYP2E1 activity. Hepatology 42:176-182. doi:10.1002/hep.20759

15. Marra F (2002) Chemokines in liver inflammation and fibrosis. Front Biosci 7:d1899-d1914

16. Slater TF, Cheeseman KH, Ingold KU (1985) Carbon tetrachloride toxicity as a model for studying free-radical mediated liver injury. Philos Trans R Soc Lond B Biol Sci 311:633-645

17. Shaker ME, Houssen ME, Abo-Hashem EM, Ibrahim TM (2009) Comparison of vitamin E, L-carnitine and melatonin in ameliorating carbon tetrachloride and diabetes induced hepatic oxidative stress. J Physiol Biochem 65:225-233. doi:10.1007/BF03180575

18. Tipoe GL, Leung TM, Liong EC, Lau TY, Fung ML, Nanji AA (2010) Epigallocatechin-3-gallate (EGCG) reduces liver inflammation, oxidative stress and fibrosis in carbon tetrachloride (CCl4)-induced liver injury in mice. Toxicology 273:45-52. doi: 10.1016/j.tox.2010.04.014

19. Shim JY, Kim MH, Kim HD, Ahn JY, Yun YS, Song JY (2010) Protective action of the immunomodulator ginsan against carbon tetrachloride-induced liver injury via control of oxidative stress and the inflammatory response. Toxicol Appl Pharmacol 242:318-325. doi:10.1016/j.taap.2009.11.005

20. Shi H, Dong L, Zhang Y, Bai Y, Zhao J, Zhang L (2010) Protective effect of a coffee preparation (Nescafe pure) against carbon tetrachloride-induced liver fibrosis in rats. Clin Nutr 29:399-405. doi:10.1016/j.clnu.2009.12.007

21. Popovic M, Vukmirovic S, Stilinovic N, Capo I, Jakovljevic V (2010) Anti-oxidative activity of an aqueous suspension of commercial preparation of the mushroom Coprinus comatus. Molecules 15:4564-4571. doi:10.3390/molecules 15074564

22. Larrey D (2000) Drug-induced liver diseases. J Hepatol 32:77-88

23. Lieber CS (2000) Alcoholic liver disease: new insights in pathogenesis lead to new treatments. J Hepatol 32:113-128

24. Ozer J, Ratner M, Shaw M, Bailey W, Schomaker S (2008) The current state of serum biomarkers of hepatotoxicity. Toxicology 245:194-205. doi:10.1016/j.tox.2007.11.021

25. Rhee SG, Chang TS, Bae YS, Lee SR, Kang SW (2003) Cellular regulation by hydrogen peroxide. J Am Soc Nephrol 14:S211S215

26. Edwards MJ, Keller BJ, Kauffman FC, Thurman RG (1993) The involvement of Kupffer cells in carbon tetrachloride toxicity. Toxicol Appl Pharmacol 119:275-279. doi:10.1006/taap.1993. 1069

27. Streetz KL, Wustefeld T, Klein C, Manns MP, Trautwein C (2001) Mediators of inflammation and acute phase response in the liver. Cell Mol Biol (Noisy-le-grand) 47:661-673

28. Smart DE, Vincent KJ, Arthur MJ, Eickelberg O, Castellazzi M, Mann J, Mann DA (2001) JunD regulates transcription of the tissue inhibitor of metalloproteinases- 1 and interleukin- 6 genes in activated hepatic stellate cells. J Biol Chem 276:24414-24421. doi:10.1074/jbc.M101840200

29. Roberts RA, James NH, Cosulich S, Hasmall SC, Orphanides G (2001) Role of cytokines in non-genotoxic hepatocarcinogenesis: cause or effect? Toxicol Lett 120:301-306

30. Zhu RZ, Xiang D, Xie C, Li JJ, Hu JJ, He HL, Yuan YS, Gao J, Han W, Yu Y (2010) Protective effect of recombinant human IL-1Ra on CCl4-induced acute liver injury in mice. World $\mathrm{J}$ Gastroenterol 16:2771-2779

31. Hoek JB, Pastorino JG (2002) Ethanol, oxidative stress, and cytokine-induced liver cell injury. Alcohol 27:63-68

32. Wahl SM, McCartney-Francis N, Chan J, Dionne R, Ta L, Orenstein JM (2003) Nitric oxide in experimental joint inflammation. Benefit or detriment? Cells Tissues Organs 174:26-33. doi:10.1159/000070572

33. Tsuchiyama T, Nakamoto Y, Sakai Y, Mukaida N, Kaneko S (2008) Optimal amount of monocyte chemoattractant protein-1 enhances antitumor effects of suicide gene therapy against hepatocellular carcinoma by M1 macrophage activation. Cancer Sci 99:2075-2082. doi:10.1111/j.1349-7006.2008.00951.x

34. Bautista AP (1997) Chronic alcohol intoxication induces hepatic injury through enhanced macrophage inflammatory protein-2 production and intercellular adhesion molecule-1 expression in the liver. Hepatology 25:335-342. doi:10.1002/hep.510250214

35. Chen X (2010) Protective effects of quercetin on liver injury induced by ethanol. Pharmacogn Mag 6:135-141. doi:10.4103/ 0973-1296.62900

36. Gewiese-Rabsch J, Drucker C, Malchow S, Scheller J, Rose-John $\mathrm{S}$ (2010) Role of IL-6 trans-signaling in $\mathrm{CCl}(4)$ induced liver damage. Biochim Biophys Acta 1802:1054-1061. doi:10.1016/ j.bbadis.2010.07.023

37. Zuinen R, Yamaji K, Aoki M, Chikuma T, Hojo H (2007) Early induced, high-level interleukin-6 expression in the rat peritoneal cavity into which a hepatotoxicant carbon tetrachloride was administered. Toxicol Lett 170:42-48. doi:10.1016/j.toxlet.2007. 02.003

38. Tsuchiya S, Tsukamoto Y, Taira E, LaMarre J (2007) Involvement of transforming growth factor-beta in the expression of gicerin, a cell adhesion molecule, in the regeneration of hepatocytes. Int J Mol Med 19:381-386

39. Bonizzi G, Karin M (2004) The two NF-kappaB activation pathways and their role in innate and adaptive immunity. Trends Immunol 25:280-288. doi:10.1016/j.it.2004.03.008

40. Gloire G, Legrand-Poels S, Piette J (2006) NF-kappaB activation by reactive oxygen species: fifteen years later. Biochem Pharmacol 72:1493-1505. doi:10.1016/j.bcp.2006.04.011

41. Liaudet L, Soriano FG, Szabo C (2000) Biology of nitric oxide signaling. Crit Care Med 28:N37-N52

42. Takada Y, Mukhopadhyay A, Kundu GC, Mahabeleshwar GH, Singh S, Aggarwal BB (2003) Hydrogen peroxide activates NF-kappa B through tyrosine phosphorylation of I kappa B alpha and serine phosphorylation of $\mathrm{p} 65$ : evidence for the involvement of I kappa B alpha kinase and Syk protein-tyrosine kinase. J Biol Chem 278:24233-24241. doi:10.1074/jbc.M212389200 